\title{
Ex vivo relaxation effect of Cuscuta chinensis extract on rabbit corpus cavernosum
}

\author{
Kai Sun ${ }^{1, *}$, Chen Zhao ${ }^{1, *}$, Xiang-Feng Chen ${ }^{1}$, Hye-Kyung Kim ${ }^{2}$, Bo-Ram Choi ${ }^{2}$, Yi-Ran Huang ${ }^{1}$ \\ and Jong-Kwan Park ${ }^{2}$
}

The effect of Cuscuta chinensis extract on the rabbit penile corpus cavernosum (PCC) was evaluated in the present study. Penises obtained from healthy male New Zealand white rabbits $\left(2.5-3.0 \mathrm{~kg}\right.$ ) were precontracted with phenylephrine (Phe, $10 \mu \mathrm{mol} \mathrm{I}{ }^{-1}$ ) and then treated with various concentrations of Cuscuta chinensis extract $\left(1,2,3,4\right.$ and $\left.5 \mathrm{mg} \mathrm{ml}^{-1}\right)$. The change in penile tension was recorded, and cyclic nucleotides in the PCC were measured by radioimmunoassay (RIA). The interaction between Cuscuta chinensis and sildenafil was also evaluated. The result indicated that the PCC relaxation induced by Cuscuta chinensis extract was concentration-dependent. Pre-treatment with an nitric oxide synthase (NOS) inhibitor (No nitro-L-arginine-methyl ester, L-NAME), a guanylyl cyclase inhibitor (1H-[1,2,4]oxadiazolo[4,3-a]quinoxalin-1-one, ODQ), or a protein kinase A inhibitor (KT 5720) did not completely inhibit the relaxation. Incubation of penile cavernous tissue with the Cuscuta chinensis extract significantly increased cyclic guanosine monophosphate (cGMP) and cyclic adenosine monophosphate (cAMP) in the PCC. Moreover, the Cuscuta chinensis extract significantly enhanced sildenafil-induced PCC relaxation. In conclusion, the Cuscuta chinensis extract exerts a relaxing effect on penile cavernous tissue in part by activating the NO-cGMP pathway, and it may improve erectile dysfunction (ED), which does not completely respond to sildenafil citrate.

Asian Journal of Andrology (2013) 15, 134-137; doi:10.1038/aja.2012.124; published online 12 November 2012

Keywords: Cuscuta chinensis; erectile dysfunction (ED); NO-cGMP pathway; penile corpus cavernosum (PCC); sildenafil

\section{INTRODUCTION}

Erectile dysfunction (ED), the persistent inability to achieve or maintain an erection for satisfactory sexual performance, is a common and important medical problem. ${ }^{1,2}$ It is estimated that ED affects more than 150 million men worldwide. ${ }^{3}$ The failure of penile erection may be due to impaired relaxation of the smooth muscle of the corpus cavernosum, which is mediated via the intracellular second messengers cyclic guanosine monophosphate (cGMP) and cyclic adenosine monophosphate (cAMP). ${ }^{4}$ Activation of cGMP/cAMP-specific protein kinases induces the opening of potassium channels and the closing of calcium channels and leads to smooth muscle relaxation.

Oral phosphodiesterase type 5 (PDE5) inhibitors are recommended as first-line therapies for ED of varied aetiology and severity., However, many men are dissatisfied with the available therapies due to their associated high cost, adverse events and perceived lack of efficacy. ${ }^{7}$ Herbal medicine approaches to a variety of diseases utilize a number of fruits and vegetables, and their use in medicine remains a vital field of study in Oriental countries. One of these herbal medicines, the dried seeds of Cuscuta chinensis Lam (Family Convolvulaceae), is an important Chinese traditional medicine widely used to improve sexual function, prevent and treat cardiovascular diseases, treat osteoporosis and prevent senescence. ${ }^{8-10}$ The active constituents of Cuscuta chinensis include flavonoids, lignans, quinic acids and polysaccharides. ${ }^{11-14}$ These compounds may be responsible for the pharmacological activities of Cuscuta chinensis. ${ }^{15}$ However, the molecular mechanism of Cuscuta chinensis in ED treatment remains unclear.

In the present study, we evaluated the effect of Cuscuta chinensis extract on the No-cGMP/cAMP signalling pathway. The interaction between Cuscuta chinensis and sildenafil citrate was also investigated.

\section{MATERIALS AND METHODS}

This research was conducted in accordance with the UK Animals (Scientific Procedures) Act of 1986 and its associated guidelines, the EEC Directive of 1986 (86/609/EEC), and the National Institutes of Health Guide for the Care and Use of Laboratory Animals (National Institutes of Health Publication No. 80-23; revised in 1978). This study was approved by the Institutional Animal Care and Use Committee of Shanghai Jiao Tong University (IRB approval No. 20110521).

\section{Plant materials}

Cuscuta chinensis seeds were collected from Baiyun Mountain, Luoyang, Henan Province, China in 2011. The voucher specimen (accession No. CC-1) was deposited at the Natural Products Research Center of Korean Institute of Science and Technology Gangneung Institute in Gangneung, Korea. The plant was identified 
and authenticated by Dr Chul Young Kim of the Korean Institute of Science and Technology Gangneung Institute.

Shade-dried Cuscuta chinensis seeds were pulverised and extracted three times with $95 \%$ ethanol. The extract was preserved through drying in a Speedvac concentrator (Savant, Farmingdale, NY, USA) and stored at $4{ }^{\circ} \mathrm{C}$ until use. The yield of dried extract from starting dried plant material was approximately $15.0 \%$.

\section{Chemicals and reagents}

$\mathrm{N} \omega$ nitro-L-arginine-methyl ester (L-NAME), 1H-[1,2,4] oxadiazolo[4,3-a]quinoxalin-1-one (ODQ), KT 5720 and L-phenylephrine (Phe) were purchased from Sigma-Aldrich (St Louis, MO, USA). Sildenafil citrate was donated from Dong A Pharmaceutical Company (Yongin, Korea). All other chemicals were purchased from standard suppliers. All of the drugs were dissolved in distilled water except KT 5720 and ODQ, which were dissolved in dimethyl sulphoxide. The highest dimethyl sulphoxide concentration in the various test systems was $<1 \%(\mathrm{v} / \mathrm{v})$. The other reagents were dissolved and diluted in an isotonic saline solution.

\section{Experimental animals}

A total of 104 male New Zealand white rabbits (12 weeks old; $2.5-3.0 \mathrm{~kg}$ ) were used in the study. The rabbits were housed individually with a 12-h light cycle at a temperature of $20{ }^{\circ} \mathrm{C}$ and $40 \%-60 \%$ humidity. The animals were fed a commercial rabbit diet ad libitum.

\section{Tissue preparation}

The tissue was prepared as previously described. ${ }^{16}$ Healthy control male New Zealand white rabbits were anaesthetised with ketamine (50 $\mathrm{mg} \mathrm{kg}^{-1}$ intravenously) plus Rompun $\left(25 \mathrm{mg} \mathrm{kg}^{-1}\right)$ and exsanguinated. The entire penis, including the urethra, was rapidly excised from the pubic bone. The urethra was dissected from the penile body. During the preparation, each step was cautiously performed to prevent damage of functional endothelium or overstretching of the tissue.

The glans penis was cut until the corpus cavernosum was exposed to air through a small opening with a diameter of $5 \mathrm{~mm}$. Two small polyethylene tubes (inner diameter $1.2 \mathrm{~mm}$ and outer diameter $1.7 \mathrm{~mm}$; Natsume, Tokyo, Japan), which contained small internal platinum electrodes, were inserted into the proximal opening of the crura for inflow and ligated with a purse string silk suture to prevent leakage. The distal cut of the corpus cavernosum was opened to allow flow out of the penis. The distal end was sutured with a cotton thread to a holder at the bottom of the chamber. The cannulated penis was mounted vertically in a 50-ml fully humidified organ chamber without buffer outside the penis. The penis was immediately perfused interstitially through the cannulae with (4-(2-hydroxyethyl) piperazine-1ethanesulfonic acid and $N$-(2-hydroxyethyl) piperazine- $N^{\prime}$-(2-ethanesulfonic acid)) (HEPES) buffer using a peristaltic pump $(0.5 \mathrm{ml}$ $\left.\min ^{-1}\right)$. The HEPES buffer contained the following (in mmol $1^{-1}$ ): $\mathrm{NaCl}, 118.0 ; \mathrm{KCl}, 4.7 ; \mathrm{CaCl}_{2}, 2.5 ; \mathrm{MgCl}_{2}, 1.2 ; \mathrm{NaHCO}_{3}$, 25.0; glucose, 10.0; and HEPES 10.0 with $\mathrm{NaOH}(\mathrm{pH}$ 7.4). The perfusion solution was oxygenated with $100 \% \mathrm{O}_{2}$ and maintained at $36{ }^{\circ} \mathrm{C}$. The hollow organ chamber was covered with Parafilm (Pechiney Plastic Packaging Company, Chicago, IL, USA) to maintain the humidity and temperature in the organ chamber at $36{ }^{\circ} \mathrm{C}$. After mounting, the tissue was equilibrated for $100 \mathrm{~min}$ with several adjustments of length until a baseline force was stabilized at $10 \mathrm{~g}$. Changes in tension were measured with a force transducer (FT03; Grass Telefactor, West Warwick, RI,
USA) and recorded using the PowerLab data 400 acquisition system (Software Chart, version 5.2; AD Instruments, Castle Hill, Austrialia).

\section{Evaluation of the cumulative dose of Cuscuta chinensis extract}

Thirty-two rabbits were used to investigate the cumulative dosedependent relaxation responses to Cuscuta chinensis extract in the PCC precontracted with Phe. A previous study has demonstrated that $10 \mu \mathrm{mol} 1^{-1}$ Phe induces PCC contraction and is effective and reliable. ${ }^{16}$ After incubation with Phe for $10 \mathrm{~min}$, the extracts were added to the medium in sequence $\left(1,2,3,4\right.$ and $\left.5 \mathrm{mg} \mathrm{ml}^{-1}\right)$ for 10 min each. To investigate the toxic effects of Cuscuta chinensis extract, we repeated the procedure after the tissue was washed for $1 \mathrm{~h}$, and the PCCs were collected after the experiments. The tissues were preincubated with L-NAME $\left(1 \mathrm{mmol}^{-1}\right)$ for $30 \mathrm{~min}$ to block NOS, preincubated with ODQ $\left(10 \mu \mathrm{mol} \mathrm{l}^{-1}\right)$ for $30 \mathrm{~min}$ to block guanylate cyclase activity or preincubated with KT $5720\left(10 \mu \mathrm{mol} \mathrm{l}^{-1}\right)$ for $30 \mathrm{~min}$ to inhibit PKA activity. Each group included right rabbits.

\section{Interaction between Cuscuta chinensis and sildenafil citrate}

Thirty-two rabbits were used to evaluate the interaction between Cuscuta chinensis and sildenafil citrate. The PCCs were preincubated with a sildenafil solution $\left(10 \mathrm{nmol} \mathrm{l}^{-1}\right)$ for $30 \mathrm{~min}$, and the Cuscuta chinensis solution $\left(2 \mathrm{mg} \mathrm{ml}^{-1}\right)$ including sildenafil citrate $\left(10 \mathrm{nmol} \mathrm{l}^{-1}\right)$ was added 10 min after Phe-induced contraction. Another penile tissue sample was preincubated with a Cuscuta chinensis solution $\left(2 \mathrm{mg} \mathrm{ml}^{-1}\right)$ for $30 \mathrm{~min}$, after which the Cuscuta chinensis solution $\left(2 \mathrm{mg} \mathrm{ml}^{-1}\right)$ including sildenafil citrate $\left(10 \mathrm{nmol} \mathrm{l}^{-1}\right)$ was added $10 \mathrm{~min}$ after Phe-induced contraction. The Cuscuta chinensis $\left(2 \mathrm{mg} \mathrm{m}^{-1}\right)$ and sildenafil citrate $\left(10 \mathrm{nmol}^{-1}\right)$ solutions were also tested individually.

Radioimmunoassay (RIA) for the cAMP and cGMP concentrations To measure the cAMP/cGMP concentration in the PCC, the penises obtained from 40 rabbits were incubated with HEPES buffer or 1, 2, 3 or $4 \mathrm{mg} \mathrm{ml}^{-1}$ of Cuscuta chinensis for $10 \mathrm{~min}$, and the PCC was then dissected free from the tunica albuginea. The samples were minced in $2 \mathrm{ml}$ of ice-cold trichloroacetic acid and homogenized at $4{ }^{\circ} \mathrm{C}$ with three 30-s bursts in a Polytron homogenizer. The homogenates were centrifuged at $1000 \mathrm{~g}$ for $10 \mathrm{~min}$ at $4{ }^{\circ} \mathrm{C}$, and the supernatant was extracted with ether and dried. The pellet was treated with $500 \mu \mathrm{l}$ $\mathrm{NaOH}\left(1 \mathrm{moll}^{-1}\right)$, ultrasonicated and used for protein determination.

The levels of cAMP and cGMP were measured with a specific RIA, as described previously. ${ }^{17}$ Briefly, standards or samples were taken up in a final volume of $100 \mu \mathrm{l}$ of $50 \mathrm{mmol}^{-1}$ sodium acetate buffer ( $\mathrm{pH} 4.8$ ) containing theophylline $\left(8 \mathrm{mmol}^{-1}\right)$, and then $100 \mu$ lof diluted cAMP antiserum (Calbiochem-Novabiochem, San Diego, CA, USA) and iodinated 2'-O-monosuccinyl-adenosine $3^{\prime}, 5^{\prime}$-cyclic monophosphate tyrosyl methyl ester (125 I-ScAMP-TME; 10000 counts per $\min (\mathrm{cpm})$ per $100 \mu \mathrm{l})$ was added to measure cAMP. Similarly, $100 \mu \mathrm{l}$ of diluted cGMP antiserum (Calbiochem-Novabiochem) and iodinated 2'-O-monosuccinyl-guanosine $3^{\prime}, 5^{\prime}$-cyclic monophosphate tyrosyl methyl ester (125 I-ScGMP-TME; $10000 \mathrm{cpm}$ per $100 \mu \mathrm{l}$ ) was added to measure cGMP and incubated for $24 \mathrm{~h}$ at $4{ }^{\circ} \mathrm{C}$. For the acetylation reaction, $5 \mu \mathrm{l}$ of a mixture of acetic anhydride and triethylamine ( $1: 2$ dilution) was added to the assay tube before the antiserum and tracer were also added. The bound form was separated from the free form by charcoal suspension. The amounts of cAMP and cGMP were expressed in femtomoles per milligram of PCC tissue. The sensitivity was $<0.5 \mathrm{pg}$ for acetylated cAMP or cGMP in a $50 \mu \mathrm{l}$ sample. The concentration of cAMP producing 50\% displacement from total binding was $1.43 \mathrm{pg}$, while it was $1.50 \mathrm{pg}$ for cGMP. 


\section{Statistical analysis}

The maximal penile contractile responses induced by Phe were taken as the $100 \%$ values, and all subsequent responses to Cuscuta chinensis were expressed as a percentage of this value. The results are expressed as mean \pm s.d. The statistical significance of the differences was calculated by a one-way analysis of variance, followed by Bonferroni's multiple comparison test. Concentration-dependent responses before and after treatment with blockers were compared by paired $t$-test. $P<0.05$ was considered statistically significant.

\section{RESULTS}

Evaluation of the cumulative dose of Cuscuta chinensis extract

The percentages of relaxation induced by $1,2,3,4$ and $5 \mathrm{mg} \mathrm{ml}^{-1}$ of Cuscuta chinensis extract were $4.26 \% \pm 0.71 \%, 32.54 \% \pm 3.28 \%$, $59.46 \% \pm 7.23 \%, 99.62 \% \pm 18.58 \%$ and $108.32 \% \pm 18.67 \%$, respectively. After washing, the tissues had the same response to Phe and Cuscuta chinensis. Pre-treatment with L-NAME, ODQ or KT 5720 did not affect the induced relaxation $(P>0.05, n=8$, Figure 1). The half maximal inhibitory concentration of Cuscuta chinensis-induced PCC relaxation was $2.53 \mathrm{mg} \mathrm{ml}^{-1}$.

\section{Effects of Cuscuta chinensis on PCC incubated with sildenafil citrate}

The relaxation induced by a single dose of sildenafil citrate $\left(10 \mathrm{nmol}^{-1}\right)$ in Phe-precontracted tissue was $45.62 \% \pm 5.74 \%$, and the use of Cuscuta chinensis $\left(2 \mathrm{mg} \mathrm{ml}^{-1}\right.$ ) alone induced $32.54 \% \pm 4.28 \%$ relaxation in Pheprecontracted tissue. The combination of Cuscuta chinensis and sildenafil citrate induced $96.33 \% \pm 9.10 \%$ relaxation in the Cuscuta chinensispreincubated tissue and $95.87 \% \pm 10.22 \%$ relaxation in the sildenafil citrate-preincubated penile tissue. Cuscuta chinensis markedly enhanced sildenafil citrate-induced relaxation $(P<0.01, n=8$, Figure 2$)$.

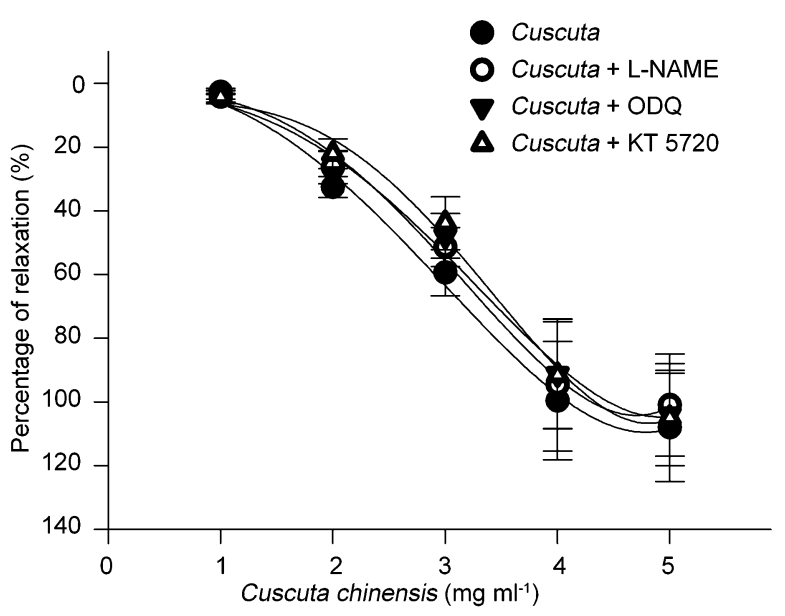

Figure 1 The percentage of relaxation induced by Cuscuta chinensis extract in a perfusion model $(n=8)$. The penile cavernosum tissue was precontracted with Phe $\left(10 \mu \mathrm{mol} I^{-1}\right)$ and treated with four concentrations of Cuscuta chinensis. The relaxation was dose-dependent. Pre-treatment with L-NAME, ODQ or KT 5720 did not completely abolish the relaxation. The maximal penile contractile responses induced by Phe were taken as the $100 \%$ values, and all subsequent responses to Cuscuta chinensis were expressed as a percentage of this value. Each point represents the mean \pm s.d. of the percentages. L-NAME, N $\omega$ nitro-Larginine-methyl ester; ODQ, 1H-[1,2,4]oxadiazolo[4,3-a]quinoxalin-1-one; Phe, phenylephrine.

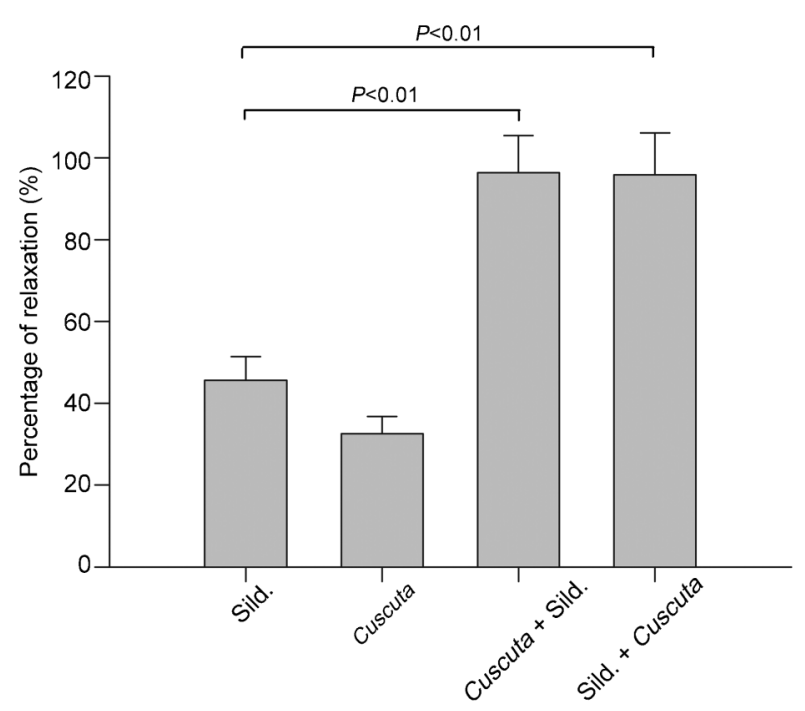

Figure 2 The percentage of relaxation induced by a combination of Cuscuta chinensis $\left(2 \mathrm{mg} \mathrm{ml}^{-1}\right)$ and sildenafil $\left(10 \mathrm{nmol} \mathrm{I}^{-1} ; n=8\right)$. The combination significantly enhanced the relaxation. There were no differences between tissues preincubated with Cuscuta chinensis or sildenafil. Each point represents the mean \pm s.d. of the percentages of maximal relaxation of the preceding maximal contractile responses. Sild. represents sildenafil.

\section{Effect of Cuscuta chinensis on cAMP/cGMP in PCC}

Both cAMP and cGMP increased in PCC tissue perfused by Cuscuta chinensis extract in a concentration-dependent manner $(P<0.01)$. The cAMP and cGMP yield peaked at a concentration of $4 \mathrm{mg} \mathrm{ml}^{-1}(n=8$, Table 1).

\section{DISCUSSION}

For erection to occur, the penile arteries and PCC have to dilate, thereby increasing the blood flow into the penis. ${ }^{3}$ Many studies have demonstrated that eNOS and nNOS activation results in NO synthesis. Released NO diffuses into smooth muscle cells and binds to guanylyl cyclase, stimulating cGMP synthesis. cGMP binding to cGMP-dependent protein kinases or cGMP-dependent ion channels results in the reduction in intracellular $\mathrm{Ca}^{2+}$, causing diminution of smooth muscle contractility and enhancing penile erection. ${ }^{18}$ In addition, cAMP has also been found to be important as an intracellular second messenger. ${ }^{19}$ Adenylyl cyclase causes an increase in the intracellular concentration of cAMP, which binds to cAMP-dependent protein kinases and acts on calcium channels to decrease the intracellular calcium concentration, leading to PCC relaxation. The

Table 1 Effect of Cuscuta chinensis on cyclic nucleotides in penile corpus cavernosum

\begin{tabular}{lcc}
\hline \multirow{2}{*}{ Cuscuta chinensis } & \multicolumn{2}{c}{ Cyclic nucleotides } \\
\cline { 2 - 3 } & cGMP $\left(\mathrm{fmol} \mathrm{mg^{-1 } )}\right.$ & cAMP $\left(\mathrm{fmol} \mathrm{mg}{ }^{-1}\right)$ \\
\hline Control & $254.1 \pm 16.9$ & $6772.1 \pm 501.3$ \\
$1 \mathrm{mg} \mathrm{ml}^{-1}$ & $301.2 \pm 18.3^{*}$ & $7412.8 \pm 563.5^{*}$ \\
$2 \mathrm{mg} \mathrm{ml}^{-1}$ & $354.9 \pm 22.9^{*}$ & $8122.6 \pm 617.1^{*}$ \\
$3 \mathrm{mg} \mathrm{ml}^{-1}$ & $401.3 \pm 28.8^{*}$ & $9223.9 \pm 601.5^{*}$ \\
$4 \mathrm{mg} \mathrm{ml}^{-1}$ & $467.1 \pm 37.5^{*}$ & $9926.1 \pm 667.7^{*}$ \\
\hline
\end{tabular}

Abbreviations: cAMP, cyclic adenosine monophosphate; cGMP, cyclic guanosine monophosphate.

$* P<0.01$ vs. control. 
inhibition of NOS or cGMP/cAMP-dependent kinase activity specifically abolishes cGMP/cAMP-induced smooth muscle relaxation.

In our study, Cuscuta chinensis significantly relaxed the corporal tissue and increased the cAMP and cGMP concentrations in the PCC tissues. These results suggest that Cuscuta chinensis may improve erectile function. The primary intracellular effector pathway for cavernous smooth muscle relaxation appears to be mediated through the NO-cGMP pathway system, and the cAMP system apparently functions as a secondary pathway. ${ }^{20}$ The cGMP/cAMP level is regulated by a balance between the rate of synthesis by guanylyl cyclase or adenylyl cyclase and the rate of hydrolytic breakdown to GMP or AMP by cyclic nucleotide phosphodiesterase isozymes, respectively. ${ }^{21}$ Therefore, agents that inhibit cGMP/cAMP hydrolysis may increase the cyclic nucleotide signal and could be expected to enhance smooth muscle relaxation in the PCC and thereby facilitate penile erection.

We hypothesized that Cuscuta chinensis-evoked relaxation would be attenuated after treatment with ODQ, L-NAME or KT 5720 if activation of the NO-cGMP/cAMP pathway was involved in the signalling pathway. However, these agents did not completely inhibit Cuscuta chinensis-induced relaxation (Figure 1), but the upregulation of eNOS and nNOS was abolished by L-NAME. Thus, we speculate that Cuscuta chinensis is partially involved in penile erection and that Cuscuta chinensis-induced relaxation occurs through additional pathways due to its multiple components.

PDE5 is the predominant enzyme responsible for cGMP hydrolysis in trabecular smooth muscle. Activation of PDE5 terminates NOinduced, cGMP-mediated smooth muscle relaxation, resulting in the restoration of basal smooth muscle contractility and penile flaccidity. Sildenafil citrate, a potent reversible and selective inhibitor of PDE5, has been widely used in the management of ED but is not without limitations. Many researchers are investigating alternative medicine to improve the homeostatic balance and erectile function. Five known compounds have been isolated and identified in Cuscuta chinensis extract: quercetin, kaempferol, isorhamnetin, hyperside and astragalin. ${ }^{22,23}$ However, the compound responsible for inducing PCC relaxation is still unknown. Therefore, further study is required to identify the effective components.

Although many drugs are now available for treating ED, identifying a new drug to treat ED and understanding its mechanism of action are still important research goals. This study only showed the relaxation effect of Cuscuta chinensis on isolated PCC, but the mechanisms involved in vivo and the pharmacokinetic/pharmacodynamic properties have to be clarified. Cuscuta chinensis enhanced sildenafil citrate-induced relaxation and may improve ED in ED patients who do not completely respond to PDE5 inhibitors.

In conclusion, Cuscuta chinensis significantly relaxed corporal tension and increased cAMP and cGMP levels in PCC tissues, suggesting that its mechanism of action partly involves the NO-cGMP pathway. Cuscuta chinensis-improved sildenafil citrate-induced relaxation may be helpful for patients who do not respond to sildenafil citrate.

\section{AUTHOR CONTRIBUTIONS}

KS performed the RIA. CZ performed the ex vivo penile perfusion study and the statistical analysis. KS, CX, XFC, HKK and BRC participated in the sequence alignment and drafted the manuscript. JKP provided the Cuscuta chinensis extract and participated in the design of the study. YRH conceived of the study, participated in its design and coordination, and helped draft the manuscript. All of the authors read and approved the final manuscript.

\section{COMPETING FINANCIAL INTERESTS}

The authors declare that they have no competing financial interests.

\section{ACKNOWLEDGMENTS}

This study was supported by a grant from Science and Technology Commission of Shanghai Municipality, China (No. 09411950300).

1 Andersson KE. Mechanisms of penile erection and basis for pharmacological treatment of erectile dysfunction. Pharmacol Rev 2011; 63: 811-59.

2 Fode M, Krogh-Jespersen S, Brackett NL, Ohl DA, Lynne CM et al. Male sexual dysfunction and infertility associated with neurological disorders. Asian J Androl 2012; 14: 61-8.

3 Francis SH, Busch JL, Corbin JD, Sibley D. cGMP-dependent protein kinases and cGMP phosphodiesterases in nitric oxide and cGMP action. Pharmacol Rev 2010, 62: 525-63.

4 Bender AT, Beavo JA. Cyclic nucleotide phosphodiesterases: molecular regulation to clinical use. Pharmacol Rev 2006; 58: 488-520.

5 Montague DK, Jarow JP, Broderick GA, Dmochowski RR, Heaton JP et al. Chapter 1 : the management of erectile dysfunction: an AUA update. J Urol 2005; 174: 230-9.

6 Wespes E, Amar E, Hatzichristou D, Hatzimouratidis K, Montorsi F et al. EAU guidelines on erectile dysfunction: an update. Eur Urol 2006; 49: 806-15.

7 Madduri SD. After two years, did Viagra live up to its expectations? Mo Med 2001; 98 243-5.

8 Wong RW, Rabie AB. Traditional Chinese medicines and bone formation-a review. J Oral Maxillofac Surg 2006; 64: 828-37.

9 Qin L, Han T, Zhang Q, Cao D, Nian H et al. Antiosteoporotic chemical constituents from Er-Xian Decoction, a traditional Chinese herbal formula. J Ethnopharmaco 2008; 118: 271-9.

10 Zheng HZ, Dong ZH, She J. Modern Study of Traditional Chinese Medicine. Beijing Xue Yuan Press of the People's Republic of China; 1998. p4110.

11 Du XM, Kohinata K, Kawasaki T, Guo YT, Miyahara K. Components of the ether-insoluble resin glycoside-like fraction from Cuscuta chinensis. Phytochemistry 1998; 48: 843-50.

12 Wang Z, Fang JN, Ge DL, Li XY Chemical characterization and immunological activities of an acidic polysaccharide isolated from the seeds of Cuscuta chinensis Lam. Acta Pharmacol Sin 2000; 21: 1136-40.

13 Ye M, Yan YN, Qiao L, Ni XM. Studies on chemical constituents of Cuscuta chinensis. Zhongguo Zhong Yao Za Zhi 2002; 27: 115-7.

$14 \mathrm{He}$ XH, Yang WZ, Meng AH, He WN, Guo DA et al. Two new lignin glycosides from the seeds of Cuscuta chinensis. J Asian Nat Prod Res 2010; 12: 934-9.

15 Ososki AL, Kennelly EJ. Phytoestrogens: a review of the present state of research. Phytother Res 2003; 17: 845-69.

16 Zhao C, Chae HJ, Kim SH, Cui WS, Lee SW et al. A new perfusion model for studying erectile function. J Sex Med 2010; 7: 1419-28.

17 Zhao C, Kim SH, Lee SW, Jeon JH, Kang KK et al. Activity of phosphodiesterase type 5 inhibitors in patients with lower urinary tract symptoms due to benign prostatic hyperplasia. BJU Int 2011; 107: 1943-7.

18 Escrig A, Gonzalez-Mora JL, Mas M. Nitric oxide release in penile corpora cavernosa in a rat model of erection. J Physiol 1999; 516: 261-9.

19 Kim NN, Huang Y, Moreland RB, Kwak SS, Goldstein I et al. Cross-regulation of intracellular CGMP and CAMP in cultured human corpus cavernosum smooth muscle cells. Mol Cell Biol Res Commun 2000; 4: 10-4.

20 Recio P, Lopez PG, Hernandez M, Prieto D, Contreras J et al. Nitrergic relaxation of the horse corpus cavernosum. Role of cGMP. Eur J Pharmacol 1998; 351: 85-94.

21 Beavo JA. Cyclic nucleotide phosphodiesterases: functional implications of multiple isoforms. Physio Rev 1995; 75: 725-48.

22 Ye M, Li Y, Yan Y, Liu H, Ji X. Determination of flavonoids in Semen Cuscutae by RPHPLC. J Pharm Biomed Anal 2002; 28: 621-8.

23 Yang L, Chen Q, Wang F, Zhang G. Antiosteoporotic compounds from seeds of Cuscuta chinensis. J Ethnopharmacol 2011; 135: 553-60. 